\title{
Catabolite Repression of Pseudomonas aeruginosa Amidase: Isolation of Promotor Mutants
}

\author{
By P. F. SMYTH AND PATRICIA H. CLARKE \\ Department of Biochemistry, University College London, London WCI E 6BT
}

(Received 2 January 1975; revised 17 March 1975)

\begin{abstract}
SUMMAR Y
Among mutants of Pseudomonas aeruginosa isolated from fluoroacetamide medium were some which synthesized amidase at about $5 \%$ of the rate of the parent constitutive strain, PACIOI. Seven fluoroacetamide-resistant mutants with low amidase activity gave rise to secondary mutant strains on succinate + butyramide plates. One appeared to be an 'up-promotor' mutant and synthesized amidase at a high rate. This mutant, PAC433, was not stimulated by cyclic-AMP and was much less sensitive to catabolite repression by succinate. The mutation conferring resistance to catabolite repression was cotransduced at a frequency of $96 \%(26 / 27)$ with the amidase genes $a m i R$, amiE. Five other revertants had catabolite repression-resistance mutations which were linked to the amidase genes and these also were probably promotor mutants. One strain had a mutation conferring resistance to catabolite repression which was unlinked to the amidase genes.
\end{abstract}

\section{INTRODUCTION}

The inducible amidase of Pseudomonas aeruginosa is subject to catabolite repression by succinate and other carbon compounds. Synthesis of the enzyme by inducible and constitutive strains is stimulated by cyclic AMP (c-AMP) which also gives partial relief to the mild repression produced by compounds such as lactate (Smyth \& Clarke, 1975). Catabolite repression-resistant mutants isolated from plates containing lactamide as nitrogen source and succinate as carbon source ( $\mathrm{S} / \mathrm{L}$ plates) carried mutations which were unlinked to the amidase genes amiRamiE. It was thought that if c-AMP affected the initiation of transcription, as in Escherichia coli, it should be possible to isolate a class of promotor mutants which would be resistant to catabolite repression and insensitive to stimulation of amidase synthesis by c-AMP. The amidase structural gene amiE is known to be closely linked to the amidase regulator gene $a m i R$, since mutations in these genes are cotransduced at frequencies $>90 \%$ (Brammar, Clarke \& Skinner, 1967). With promotor mutants it would be predicted that the mutations conferring resistance to catabolite repression would be cotransduced with the amiE gene at frequencies approaching $100 \%$.

\section{METHODS}

Bacterial strains and media. The strains used in this study were from $P$. aeruginosa PACI and are listed in Tables I to 3. Culture methods and media were as described by Smyth \& Clarke (I975), with the addition of fluoroacetamide and pyruvate plates (Clarke \& Tata, I973) and succinate + butyramide plates (S/B) which contained $\mathrm{I} \cdot 0 \%(\mathrm{w} / \mathrm{v})$ sodium succinate and $0.05 \%(\mathrm{w} / \mathrm{v})$ butyramide.

Growth conditions and enzyme assays were as in Smyth \& Clarke (I975). 
Table I. Mutants isolated from succinate + butyramide $(S / B)$ medium

\begin{tabular}{|c|c|c|c|c|c|}
\hline Strain no.* & Series no. & Phenotype $\nmid$ & $\begin{array}{c}\text { Amidase } \\
\text { specific activity } \ddagger\end{array}$ & B/A ratio $\S$ & Growth on S/B \\
\hline PACI & WT & $\begin{array}{l}\text { Ind AmiA } \\
\text { Crp-s But-s }\end{array}$ & NA & NA & 0 \\
\hline PACI I I & CI I & $\begin{array}{l}\text { Con AmiA } \\
\text { Crp-s But-s }\end{array}$ & $14-20$ & $0.3-0.6$ & 0 \\
\hline PAC35 I & B6 & $\begin{array}{l}\text { Con AmiB } \\
\text { Crp-s But-s }\end{array}$ & $14-16$ & $9-12$ & + \\
\hline \multirow[t]{3}{*}{ PACI42 } & LIO & $\begin{array}{l}\text { Con AmiA } \\
\text { Crp-r But-r }\end{array}$ & $55-70$ & $0.3-0.6$ & + \\
\hline & SBI -62 & $\begin{array}{l}\text { Con AmiA } \\
\text { Crp-r But-r }\end{array}$ & $30-160$ & $0.3-0.6$ & + \\
\hline & SB63-92 & $\begin{array}{l}\text { Con AmiB } \\
\text { Crp-s But-s }\end{array}$ & IO-I5 & $8-$ I I & + \\
\hline
\end{tabular}

NA, Not applicable.

* Mutants SBI to SB92 isolated from strain PACI following NTG mutagenesis were not added to the collection, so no strain numbers were assigned.

$\dagger$ Phenotype abbreviations: Ind, inducible; Con, constitutive; AmiA, wild-type A amidase; AmiB, mutant B amidase; Crp-s and Crp-r, sensitive or resistant to catabolite repression; But-s and But-r, sensitive or resistant to butyramide repression.

$¥$ Determined after overnight growth in succinate medium.

$\S \mathrm{B} / \mathrm{A}$ ratio is butyramide activity as a percentage of acetamide activity, determined with whole cells by using the transferase assay of Betz et al. (1974).

Transduction. The method used was that described by Brammar et al. (1967) using bacteriophage Fi 6 .

Mutagenesis. Treatment with $N$-methyl- $N^{\prime}$-nitro- $N$-nitrosoguanidine (NTG) was carried out as described by Brown, Brown \& Clarke (1969).

\section{RESULTS}

\section{Isolation and characterization of catabolite repression-resistant mutants}

The amidase regulatory system of $P$. aeruginosa is exceptional in that it has proved to be possible to isolate large numbers of mutants showing some degree of resistance to catabolite repression. Media which have been successfully used for this purpose include minimal agar plates containing succinate, malate or glucose as carbon source and lactamide as the nitrogen source for growth. These media allow the growth of many different classes of mutants carrying mutations, unlinked to the amidase genes, which could be at various different gene loci. Some of these mutations can be ascribed to metabolic defects in pathways for the utilization of carbon sources (Smyth \& Clarke, 1975). However, if amidase synthesis is activated in the same way as $\beta$-galactosidase, it would be expected that some of the mutations affecting catabolite repression might be in a gene determining the c-AMP receptor protein (CRP), in a gene determining the synthesis of adenyl cyclase or in the promotor of the structural gene for the enzyme itself (De Crombrugghe et al. 197I ; Emmer et al. 1970; Zubay, Schwartz \& Beckwith, 1970). Only promotor mutations would be expected to be linked to the amidase genes.

Lactamide, although a very poor substrate, is an excellent inducer and supports good growth of the wild type when used as source of both carbon and nitrogen. Succinate 
represses amidase synthesis, and therefore growth on S/L plates, but the disadvantages of this medium are not only that the wild type and most constitutive strains give some background growth, but also that too many different classes of catabolite repression-resistant mutants are selected. It was thought that one of the other amides might be combined with succinate to give a medium which would offer more discrimination between the different classes of mutants. Butyramide seemed the most suitable for this purpose, since it is a very poor substrate and does not support even trace growth of the wild type when used as the sole growth substrate. Butyramide is thought to combine with the regulator protein without allowing amidase synthesis to occur, since it prevents enzyme induction by $N$-acetylacetamide and represses amidase synthesis in many constitutive strains. Some constitutive strains are known to be resistant to repression by butyramide (Brown \& Clarke, 1970).

Several mutants were tested to see if they could be grown on S/B plates; of the strains producing wild-type A amidase, only those which, like PACI42 (LIO), were at the same time constitutive, resistant to butyramide repression and resistant to catabolite repression, were able to do so. In addition, strain PAC35I (B6), which is constitutive and produces a mutant amidase with a much higher rate of butyramide hydrolysis, was able to grow on S/B plates although it had not lost sensitivity to butyramide repression or to catabolite repression by succinate.

Mutants appeared spontaneously on S/B plates when a constitutive butyramide-resistant strain was used as the parent, but none were obtained directly from the wild type or from constitutive butyramide-sensitive strains which would be expected to need at least two mutations to gain this phenotype. Table I shows that mutants isolated from the wild-type strain on S/B plates after mutagenic treatment with NTG fell into two classes. Mutants SBI to SB62 produced A amidase and were similar in phenotype to PACI42. Three of these had specific activities of $>100$ after overnight growth in succinate medium. However, all three mutants had very low growth rates on succinate and were presumed to be defective in some aspect of succinate metabolism, but the other mutants were not examined in detail for growth-rates. Mutants SB63 to SB92 had specific activities after overnight growth in succinate medium which were similar to those of strain PAC35I (B6). The ratio of transferase activity for butyramide as compared with acetamide (B/A ratio) was characteristic of that for mutants producing the B amidase with altered substrate specificity. The medium had therefore also allowed the selection of constitutive, altered enzyme mutants which carried at least one mutation in the structural gene and, in addition, at least one mutation in the regulator gene directly from the wild-type strain. These mutants were not investigated further to see whether all their B-type enzymes were identical, as had been found previously for B mutants isolated from the constitutive strain CI I by Brown et al. (1969).

Nineteen mutants of the SBI to SB62 group were tested to see if any of the mutations conferring resistance to catabolite repression could be shown to be linked to the amidase structural and regulator genes, since this would indicate whether or not they might be promotor mutants. Lysates of bacteriophage FI 6 were prepared on the I9 SB mutants and used to transduce an acetamide-negative strain PAC308. Of 328 transductants resulting from these crosses, all were acetamide-positive and constitutive but none grew on S/B plates, which indicated that the catabolite repression-resistance marker had not been cotransduced and was carried by an unlinked gene. It was possible that among the rest of the mutants in the SBI to SB62 group were some which had promotor site mutations. However, since this medium had selected several other types of unlinked catabolite repression-resistant mutations it was decided not to continue screening SB mutants but to try an indirect approach. The S/B medium had been found to be very satisfactory for the isolation and screening of 
mutants with a catabolite repression-resistant phenotype since unlike the $\mathrm{S} / \mathrm{L}$ medium used previously, the background growth was negligible. It was thought the $\mathbf{S} / \mathrm{B}$ medium should continue to be used, and might select pleiotropic resistant mutants for several catabolic enzymes, but that the chances of finding an amidase-specific promotor site mutation might be greater if an amidase-defective mutant was used as the parent strain.

\section{Isolation of catabolic repression-resistant mutants from fluoroacetamide mutants}

A positive selection method which has been used for the isolation of acetamide-negative strains utilizes fluoroacetamide which inhibits growth of strains with high amidase activity. Fluoroacetamide is hydrolysed to fluoroacetate which is presumably converted to fluorocitrate, thereby blocking the tricarboxylic acid cycle and preventing growth (Clarke \& Tata, I973). Among the fluoroacetamide-resistant mutants are some which have low amidase activity and can grow on acetamide, but not on lactamide which is a much poorer substrate. These would be expected to include structural and regulator gene mutants as well as promotor mutants. Some of the 'down-promotor' mutants might be resistant to catabolite repression but screening for this property would be very laborious.

It was predicted that the most suitable parent strain would be a constitutive, butyramideresistant amidase mutant, and that some of the fluoroacetamide-resistant mutants derived from it might give rise to revertants on S/B plates with both normal amidase activity and resistance to catabolite repression determined by a promotor site mutation. The reason for choosing a constitutive parent strain which already carried resistance to butyramide repression was that this would eliminate the requirement for a regulator gene mutation allowing growth on butyramide. NTG was chosen as the mutagen since it is known to produce multiple closely-linked mutations. It was thought that if the first mutation to fluoroacetamide resistance had been in the promotor region then the second step to allow growth on S/B medium could involve additional mutations at nearby sites.

It must be emphasized that it is not essential for the first mutation resulting in low amidase activity to be a promotor mutation. With this selection procedure it would be possible to isolate mutants from strains carrying certain structural or regulatory gene mutations. Further, the S/B medium would not be expected to select only promotor mutants and the subsequent critical tests to be carried out on any mutants selected would be (i) level of resistance to catabolite repression, (ii) response to c-AMP, and (iii) linkage of the mutation to the amidase structural and regulator genes.

Fluoroacetamide-resistant mutants, spontaneous or following NTG treatment, were selected from strains PACIOI (CI), (resistant to butyramide repression) and strain PACIII (CII) (sensitive to butyramide repression). Strains CI and CI I both gave fluoroacetamide mutants which could be assigned to groups I, II and III and there appeared to be relatively more acetamide-negative group III mutants when NTG was used as the mutagen (Table 2). They were re-isolated as single colonies and tested for growth on acetate, acetamide and lactamide. All the mutants selected grew on acetate, but on acetamide plates they could be grouped into three classes: group I, good growth; group II, moderate growth; group III, poor to zero growth. Very few of the mutants isolated in this experiment grew on lactamide plates. Two of the mutants from group I which grew almost as well as the wild type on acetamide plates, but not at all on lactamide plates, were tested further. The amidase specific activities after overnight growth in pyruvate medium were about $5 \%$ of that of the parent strain. This is similar to that obtained for $\beta$-galactosidase for certain promotor mutants of the lac operon of Escherichia coli in which the rate of initiation of transcription of lac mRNA is very low (Ippen et al. 1968). Three of the acetamide-negative mutants from 
Table 2. Properties of mutants isolated from pyruvate + fuoroacetamide plates

\begin{tabular}{|c|c|c|c|c|c|c|c|c|}
\hline \multirow{3}{*}{$\begin{array}{c}\text { Parent } \\
\text { strain no. }\end{array}$} & \multirow[b]{3}{*}{ Series no. } & \multirow[b]{3}{*}{ Mutagen } & \multirow{3}{*}{$\begin{array}{l}\text { No. } \\
\text { isolated }\end{array}$} & \multicolumn{5}{|c|}{ No. growing on } \\
\hline & & & & \multicolumn{3}{|c|}{ Acetamide } & \multirow[t]{2}{*}{ Lactamide } & \multirow[t]{2}{*}{ Acetate } \\
\hline & & & & I & II & III & & \\
\hline \multirow[t]{2}{*}{ PACIII } & \multirow[t]{2}{*}{ CII } & \multirow{2}{*}{$\begin{array}{l}\text { Spontaneous } \\
\text { NTG }\end{array}$} & 78 & 37 & 30 & I I & 8 & 78 \\
\hline & & & 75 & 14 & II & 50 & 9 & 75 \\
\hline PACIII & CII & Spontaneous & 152 & 13 & $2 I$ & II 8 & ND & 152 \\
\hline \multirow{2}{*}{ PACIOI } & \multirow[t]{2}{*}{$\mathrm{CI}$} & \multirow{2}{*}{$\begin{array}{l}\text { Spontaneous } \\
\text { NTG }\end{array}$} & 80 & 10 & 48 & 20 & 2 & 80 \\
\hline & & & 44 & IO & II & 23 & 6 & 44 \\
\hline
\end{tabular}

Table 3. Properties of revertants selected on succinate + butyramide plates

$\begin{array}{clcccc}\begin{array}{c}\text { Parent } \\ \text { strain }\end{array} & \text { Mutagen } & \begin{array}{c}\text { Fluoracetamide } \\ \text { mutant }\end{array} & \text { Mutagen } & \text { S/B revertant } & \begin{array}{c}\text { Amidase specific } \\ \text { activity* }\end{array} \\ \text { PACIOI } & \text { Spontaneous } & \text { PAC420 } & \text { NTG } & \text { PAC426 } & 50 \\ & \text { Spontaneous } & \text { PAC42 I } & \text { NTG } & \text { PAC427 } & 36 \\ & \text { Spontaneous } & \text { PAC422 } & \text { NTG } & \text { PAC428 } & 42 \\ & \text { Spontaneous } & \text { PAC423 } & \text { NTG } & \text { PAC429 } & 36 \\ & \text { Spontaneous } & \text { PAC424 } & \text { NTG } & \text { PAC430 } & 45 \\ & \text { Spontaneous } & \text { PAC425 } & \text { NTG } & \text { PAC43 I } & 50 \\ \text { PACIOI } & \text { NTG } & \text { PAC432 } & \text { Spontaneous } & \text { PAC433 } & \text { I00-I 29 } \\ \text { PAC142 } & - & - & - & - & \text { I2-24 }\end{array}$

* Amidase specific activities of revertants were determined after overnight growth in succinate medium.

Table 4. Differential rates of amidase synthesis of SB revertants in pyruvate medium and repression by succinate

$\begin{array}{clcc}\text { Strain no. } & \text { Series no. } & \begin{array}{c}\text { Differential rate } \\ \text { of amidase synthesis }\end{array} & \begin{array}{c}\text { Repression } \\ \text { by succinate (\%) }\end{array} \\ \text { PACIOI } & \text { CII } & 100 & 89 \\ \text { PAC427 } & \text { CIAm2Irev } & 73 & 78 \\ \text { PAC428 } & \text { CIAm22rev } & 35 & 42 \\ \text { PAC429 } & \text { CIAm23rev } & 59 & 6 \text { I } \\ \text { PAC433 } & \text { CIAm26rev } & \text { I43 } & 65\end{array}$

group III were tested in the same way and were found to have no detectable amidase activity. It was thought that the promotor mutants were most likely to be found among those belonging to groups I or II with low rates of amidase synthesis. We tested I I 6 lactamidenegative mutants selected from strain CI (Table 2) for spontaneous reversion on lactamide, and all mutants which had a high spontaneous reversion rate were discarded. The rest were tested for the production of mutants on S/B plates in the presence of NTG. Only six strains gave rise to mutant colonies and these were all from spontaneous group II mutants. Many of the strains gave a few spontaneous revertants on lactamide plates and some of these were tested to see if they could also grow on S/B plates. The only mutant strain to be isolated in this way was PAC433, which was derived from an amidase-defective strain of group II obtained by NTG treatment of CI (Table 3). 


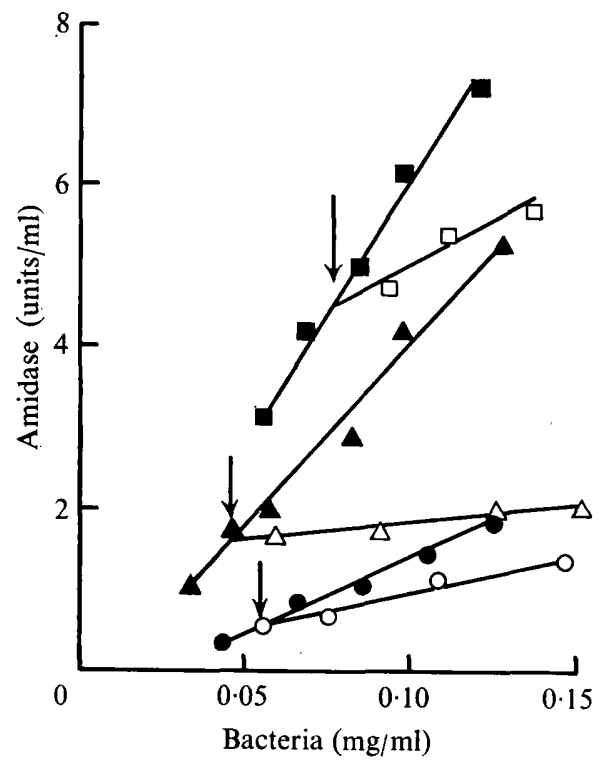

Fig. I

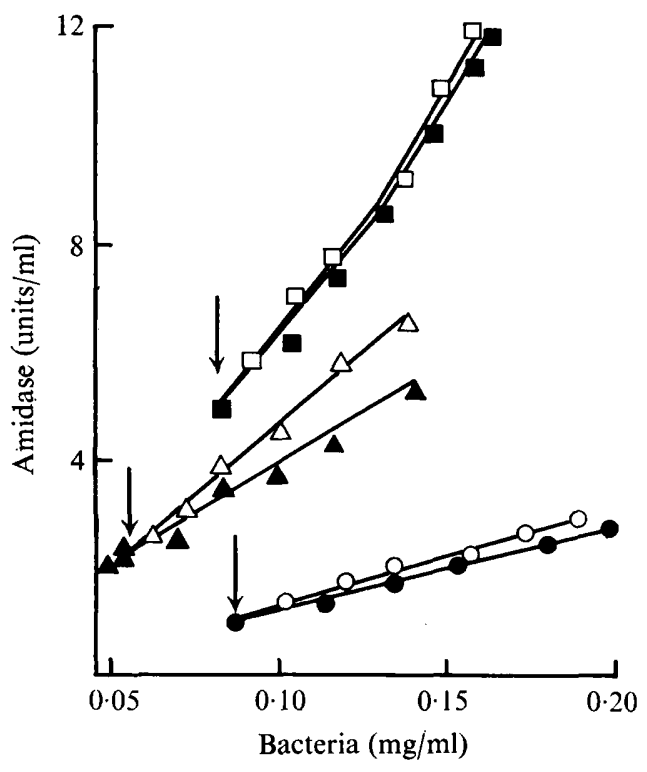

Fig. 2

Fig. I. Differential rates of amidase synthesis in pyruvate medium and the effect of succinate on

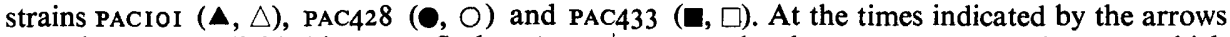
the cultures were divided into two flasks: $\Delta, 0, ' \square$, control cultures; $\triangle, O, \square$, cultures to which 10 mM-succinate had been added.

Fig. 2. The effect of c-AMP on amidase synthesis in pyruvate medium of strains PACroI $(\boldsymbol{\Delta}, \Delta)$, PAC428 $(O, O)$ and PAC433 $(\square, \square)$. At the times indicated by the arrows the cultures were divided into two flasks: $\Delta, \boldsymbol{\square}, \mathbf{\square}$, control cultures; $\triangle, 0, \square$, cultures to which $30 \mathrm{mM}$-c-AMP had been added.

\section{Properties of revertant strains isolated from $S / B$ plates}

The revertants from S/B plates were grown overnight in succinate medium and the specific activities of the cultures assayed (Table 3). All seven mutants had B/A ratios of $<\mathrm{I} \%$, indicating that the amidases were similar in specificity to the wild-type $\mathrm{A}$ amidase of the parent strain and not the mutant $B$ amidase. The values for the specific activities were all higher than that for the parent strain, suggesting that all these mutants were less sensitive to catabolite repression. This was investigated in more detail for four of the mutants, by comparing the differential rates of amidase synthesis in pyruvate medium and the extent of repression resulting from the addition of succinate to the exponentially-growing cultures. Three of the mutants, PAC427, PAC428 and PAC429, had differential rates of amidase synthesis less than that of PACIOI, but mutant PAC433 had a markedly higher rate. The growth rates of all four mutants in pyruvate medium and the changes in growth rates after the addition of succinate were identical to that found for strain PACIOI (Fig. I and Table 4).

\section{Effect of c-AMP on amidase synthesis}

Cyclic AMP stimulates the rate of amidase synthesis of both inducible and constitutive strains of $P$. aeruginosa (Smyth \& Clarke, 1975). Figure 2 shows that it had no effect on the rate of amidase synthesis of strain PAC433 and only a slight effect on strain PAC428. This is consistent with the view that the mutation(s) allowing these mutants to grow on S/B plates conferred both resistance to catabolite repression and independence of stimulation by c-AMP. 
Table 5. Genetic analysis of promotor mutants

\begin{tabular}{|c|c|c|c|c|c|}
\hline \multirow[b]{3}{*}{ Donor strain } & \multicolumn{4}{|c|}{ Transductants* } & \multirow{3}{*}{$\begin{array}{l}\text { Percentage } \\
\text { linkage }\end{array}$} \\
\hline & \multirow[b]{2}{*}{ No. tested } & \multicolumn{3}{|c|}{ No. growing on } & \\
\hline & & $\mathrm{AM}$ & $\mathrm{S} / \mathrm{F}$ & $\mathrm{S} / \mathrm{B}$ & \\
\hline PACI & 5 & 5 & 0 & 0 & - \\
\hline PACIOI & 24 & 24 & 22 & 0 & 一 \\
\hline PAC35 I & 10 & Io & 10 & 10 & - \\
\hline PAC426 & 10 & IO & ND & Io & 100 \\
\hline PAC427 & 98 & 98 & 98 & 98 & 100 \\
\hline PAC428 & 101 & IOI & IOI & IOI & 100 \\
\hline PAC429 & 56 & 56 & 55 & 55 & 99 \\
\hline PAC430 & 10 & 10 & ND & 10 & 100 \\
\hline PAC43I & 10 & 10 & ND & 0 & 0 \\
\hline PAC433 & 27 & 27 & 26 & 26 & 96 \\
\hline
\end{tabular}

ND, Not determined.

* AM, acetamide medium; S/F, succinate + formamide medium; S/B, succinate + butyramide medium.

Table 6. Properties of the transductants obtained with the amidase promotor mutants as donors

Specific activities were determined by the transferase reaction after overnight growth in succinate medium.

\begin{tabular}{ccc} 
& \multicolumn{2}{c}{ Specific activity } \\
\cline { 2 - 3 } Strain no. & Donor strain & Transductants \\
PACIOI & IO & I I \\
PACI42 & 44 & ND \\
PAC427 & 45 & 43,46 \\
PAC428 & 42 & 39,42 \\
PAC429 & 33 & 37,38 \\
PAC433 & IOI & 97,105 \\
& ND, Not determined.
\end{tabular}

\section{Genetic analysis by transduction for linkage of the catabolite repression-resistance mutation}

Lysates of bacteriophage FiI 6 were prepared on strains PAC426 to PAC43I and on strain PAC433, and were used to transduce the amidase-negative strain PAC308. Transductants were selected on acetamide plates and ten from each of the crosses were picked off and after re-isolation were tested for growth on S/B plates. The transductants from all the crosses grew well on S/B plates, except for those obtained with strain PAC43I as donor. This was examined in more detail with four of the mutants, to establish unequivocally that the mutation allowing growth on S/B plates was linked to the known amidase genes. Table 5 shows that cotransduction was 96 to $100 \%$. This close linkage was consistent with promotor site mutations conferring resistance to catabolite repression. To confirm these findings, single colony isolates of the transductants from some of these crosses were grown overnight in succinate medium and it was found that the specific activities of the transductants were the same as those of the donor strains (Table 6).

It was concluded that strains PAC427, PAC428, PAC429 and PAC433 were probably amidase promotor mutants. Strains PAC426 and PAC430 were also thought to be promotor mutants but strain PAC43 I certainly owes its resistance to catabolite repression to an unlinked mutation. 


\section{DISCUSSION}

The lac promotor mutants isolated by Scaife \& Beckwith (I966) were characterized by a very low rate of $\beta$-galactosidase synthesis and some of these were insensitive to catabolite repression (Ippen et al. 1968; Silverstone et al. 1969). Revertants of some of the lac promotor mutants with a second mutation in the promotor region had very high rates of $\beta$-galactosidase synthesis which were unaffected by the presence of glucose. We concluded that six of the amidase mutants which we describe in this paper are probably promotor mutants since they carry mutations linked very closely to the amidase structural genes which determine resistance to catabolite repression. One of them had a very high rate of amidase synthesis and could be described as an 'up-promotor' mutant, while the others synthesized amidase at rates lower than that of the constitutive strain from which they were derived. The lack of response to c-AMP of the mutant PAC433 would suggest that amidase synthesis in $P$. aeruginosa may be under the same type of control as that of some of the catabolic enzymes of $E$. coli.

The method used to isolate the promotor mutants was based on the assumption that some mutants with low rates of amidase synthesis would be promotor mutants, and might revert to a more normal amidase phenotype by a second mutation in the promotor which would also confer resistance to catabolite repression. However, although the properties of the six mutants we have described are consistent with them being promotor mutants, it is not legitimate to conclude that both the first and the second mutational steps involved promotor site mutations. The second selection in all cases, except for mutant PAC433, involved mutagenesis with NTG and could have resulted in the restoration of a mutation in either the $a m i E$ or $a m i R$ gene accompanied by a mutation in the promotor. The enzyme produced by all the presumed promotor mutants was wild type in its general properties, and the regulator phenotype (apart from resistance to catabolite repression) was similar to that of the original parent PACIOI.

Strain PAC43I as donor gave rise to transductants which were similar to strain PACIOI and none of which were resistant to catabolite repression. This suggests that the catabolite repression resistance in this strain was in an unlinked gene. This could have been a gene determining a general activator protein, since in this instance there seemed to be no alteration in rates of growth in succinate medium. We have not yet isolated a series of mutants which are pleiotropically derepressed for the synthesis of several catabolic enzymes, but one of the fluoroacetamide mutants isolated from PACIOI is defective for growth on histidine, ornithine and proline as well as acetamide (Potts, 1975). Screening revertants from more mutants of this type may make it possible to identify a gene determining a regulator protein for catabolic genes.

Mutants producing the B amidase were first isolated by Brown et al. (I969) from the constitutive mutant PACI I a and the selection depended on exploiting the sensitivity of this strain to amide analogue repression. Growth on butyramide can occur either by a mutation giving resistance to butyramide repression, or by a mutation resulting in an altered enzyme with more activity towards butyramide. During the selection for catabolite repressionresistant mutants it was found that the severe selection pressure imposed by the S/B medium was also suitable for the isolation of the altered enzyme mutants. We consider that in the isolation of mutants from the wild-type strain on S/B plates following mutagenesis with NTG, a minimum of two mutations must occur. In the first group a mutation in amiR giving constitutivity and resistance to butyramide repression was accompanied by an unlinked mutation (at least in the mutants tested) to give the catabolite repression-resistant 
phenotype. In the second group a mutation in $a m i R$ which resulted in constitutivity was accompanied by a mutation in $a m i E$ producing an altered enzyme.

It is particularly important for omnivorous bacteria such as the Pseudomonas species to have adequate regulation of the synthesis of their catabolic enzymes. In addition to the induction and repression controls which are operon specific, it seems that many enzymes are under the more general control of catabolite repression. Further studies with other catabolic enzymes should reveal whether the mechanism we have suggested for amidase regulation involving c-AMP is involved in the regulation of other operons.

We are grateful to Mrs R. Tata for assistance in mutant isolation. P.F.S. was in receipt of a Research Training grant from the Medical Research Council.

\section{REFERENCES}

Betz, J. L., Brown, J. E., Clarke, P. H. \& Day, M. (1974). Genetic analysis of amidase mutants of Pseudomonas aeruginosa. Genetical Research 23, 335-359.

Brammar, W. J., Clarke, P. H. \& Skinner, A. J. (1967). Biochemical and genetic studies with regulator mutants of the Pseudomonas aeruginosa amidase system. Journal of General Microbiology 47, 87-102.

Brown, J. E., Brown, P. R. \& Clarke, P. H. (1969). Butyramide-utilizing mutants of Pseudomonas aeruginosa which produce an amidase with altered substrate specificity. Journal of General Microbiology 57, 273-285.

BRoWN, J. E. \& ClARKE, P. H. (1970). Mutations in a regulator gene allowing Pseudomonas aeruginosa 8602 to grow on butyramide. Journal of General Microbiology 64, 329-342.

Clarke, P. H. \& TAta, R. (1973). Isolation of amidase-negative mutants of Pseudomonas aeruginosa by a positive selection method using an acetamide analogue. Journal of General Microbiology 75, 23I-234.

De Crombrugghe, B., Chen, B., Anderson, W., Nissley, P., Gottesman, M., Pastan, I. \& Perlman, R. L. (197I). Lac DNA, RNA polymerase and cyclic AMP receptor protein, cyclic AMP, lac repressor and inducer are the essential elements for controlled lac transcription. Nature, New Biology 23o, 139-142.

Emmer, M., de Crombrugghe, B., Pastan, I. \& Perlman, R. (1970). Cyclic AMP receptor protein of E. coli: its role in the synthesis of inducible enzymes. Proceedings of the National Academy of Sciences of the United States of America 66, 480-487.

IpPen, K., Miller, J. H., SCAife, J. \& Beckwith, J. (I968). New controlling element in the lac operon of E. coli. Nature, London 217, 825-827.

Ports, J. R. (1975). Histidine catabolism in Pseudomonas aeruginosa. Ph.D. thesis, University of London.

SCAIFE, J. \& BECKWITH, J. R. (1966). Mutational alteration of the maximal level of lac operon expression. Cold Spring Harbor Symposia on Quantitative Biology 31, 403-408.

Silverstone, A. E., Magasanik, B., Reznikoff, W. S., Miller, J. H. \& Beckwith, J. (1969). Catabolite sensitive site of the lac operon. Nature, London 221, I0I2-IOI4.

Smyth, P. F. \& Clarke, P. H. (1975). Catabolite repression of Pseudomonas aeruginosa amidase: the effect of carbon source on amidase synthesis. Journal of General Microbiology 90, 8I-90.

Zubay, G., Schwartz, D. \& BeCKwIth, J. (1970). Mechanism of activation of catabolite-sensitive genes. A positive control system. Proceedings of the National Academy of Sciences of the United States of America 66, I04-IIO. 